\title{
Rethinking Disadvantage: a social capital approach to Widening Participation ${ }^{1}$
}

\author{
Dr Matthew Johnson, ${ }^{2}$ Gareth Bowden ${ }^{3}$ and Guillermo Alonso ${ }^{4}$
}

This is an Author's Original Manuscript (AOM) of an article published by Ingenta in Journal of Widening Participation and Lifelong Learning, available online:

\begin{abstract}
In England and Wales, the introduction of $£ 9,250$ Higher Education tuition fees and concern more broadly about social mobility has led to the creation of a series of initiatives aimed at Widening Participation. Increasingly, critics argue that these initiatives have failed to achieve genuine representativeness, with lower ranked universities absorbing higher numbers of students from under-represented groups, who then face additional challenges in securing progression to employment. In this article, we examine dominant narratives Widening Participation programmes in England and Wales in order to assert means of widening more effectively access, in the first instance, but also retention and progression. Rejecting non-subject-specific instrumental approaches that focus directly on graduate labour market value and earnings, we argue that effective Widening Participation ought to focus centrally on the institutional value of Higher Education and on fostering social capital, especially in lower ranked universities whose graduates are already discriminated against in the labour market. To this end, we evaluate deployment of a Politics-based Widening Participation programme, Rethinking Disadvantage, asserting a set of conclusions for colleagues in other disciplines and institutions seeking to develop their own approaches.

Keywords: Widening Participation; Disadvantage; Social Capital; institutionalisation
\end{abstract}

The introduction of $£ 9,250$ tuition fees and concern more broadly about social mobility has incentivised the creation of a series of initiatives aimed at Widening Participation (WP) in Higher Education (HE). Increasingly, critics (Boliver, 2010; Johnson, 2018) argue that these initiatives have failed to achieve genuine representativeness, with lower ranked universities absorbing higher numbers of students from under-represented groups, who then face additional challenges in securing progression to employment (Department for Education, 2017). The under-represented groups referred to in the context of WP are those from lower socio-economic groups, communities and schools with low-levels of HE participation, and first-generation HE candidates (OFFA, 2018). In this article, we examine dominant narratives and operational priorities in WP programmes in England and Wales in order to assert means of widening, more effectively, access, retention and progression. We argue that there is a tendency in some schools-based WP programmes to focus on instrumental, monetary considerations, asserting the importance of qualifications to career progression, particularly in lower ranked universities which recruit a disproportionate number of students from under-represented groups.

Tracing a set of examples from different universities, we contend that WP is better served by focusing centrally on the holistic institutional benefit of HE, particularly within the context of a) the increasing value that HE institutions put on their services through rising tuition fees (on the basis that, when the price of a service is increased from, for example, $£ 9,000$ per year to $£ 9,250$ a year, there is a clear implication that the service is worth $2.8 \%$ more than previously) and, b) the class pay gap that persists among university graduates (Social Mobility

\footnotetext{
${ }^{1}$ Ethical Approval was provided by Lancaster University Faculty of Arts and Social Sciences and Lancaster University Management School Research Ethics Committee (Reference number: FL17005).

${ }^{2}$ Senior Lecturer in Politics, Department of Politics, Philosophy and Religion, Lancaster University

${ }^{3} \mathrm{PhD}$ Student, Lancaster University

${ }^{4}$ BA Hons Student, Lancaster University
} 
Commission, 2017). We engage with the social capital literature in order to map out the value of institutionalisation to individuals, highlighting the ways in which disadvantage is often bound up with exclusion from institutions to which those from advantaged backgrounds have access throughout their lives. Counter-intuitively, we argue that those institutions that do most to provide access to HE for students from disadvantaged backgrounds are those that need most to advance an institutional case but those that present that case least or least effectively at present.

We then use a Politics-based WP programme, 'Rethinking Disadvantage', as a case study around which to challenge deficits in present models by emphasising the institutional basis of disadvantage and the importance of institutionalisation as a means of challenging disadvantage through HE. By engaging with student feedback, we highlight the various challenges of deploying such a programme within the present climate. We begin by establishing the practice context in England and Wales.

\section{Understanding context: disadvantage and labour value in England and Wales}

University fees in England and Wales have risen periodically since publication of the Labour Government's response to the 1997 Dearing Report, Higher Education for the 21st Century (Department for Education and Employment, 1998), which heralded the introduction of $£ 1,000$ tuition fees. In 2004, institutions with access plans approved by the Office for Fair Access (OFFA), were permitted to raise fees to $£ 3,000$ per academic year, which rose to $£ 9,000$ in 2012 and stands presently at $£ 9,250$. Confounding the 2010-2015 Coalition Government's assertion that increasing the fees cap would foster market competition (and downward pressure on fees) among HE providers, institutions of varying repute have shown themselves fundamentally committed to charging maximum fees. While the average fees charged across England in $2012 / 13$ stood at $£ 8,400$, by $2016 / 17$ this figure had increased to $£ 8,900$ and, accordingly to $2017 / 18$ estimates, now stands at $£ 9,110$, with 121 out of 123 HE institutions charging the maximum fee of $£ 9,250$ (Bolton, 2018: 3 ). The total value of Tuition Fee Loans in England has, therefore, risen from $£ 2.6$ billion in 2012/13 to $£ 9$ billion in 2017/18 (Bolton, 2018: 9-10).

One understandable expectation arising from the marketisation of $\mathrm{HE}$ and increase in fees is an attendant increase in the real value of study to consumers (students) and businesses. If fees are rising ever higher, it is not unreasonable to expect that the value of HE study increases the value of graduates in the labour market and increases earnings overall. Universities themselves are keen to advance this expectation. For example, Lancaster University states that 'an impressive $97 \%$ of Lancaster graduates are either in employment or further study three and a half years after graduating' and that ' $85 \%$ of graduates were in graduate-level work or further study within six months of graduating' (Lancaster University, 2018).

With the premium that HE institutions put on access to their services, and with the marketing of the apparent instrumental benefits of this access, there has been recognition by Government and by HE institutions themselves that universities have a responsibility to widen participation, assisting people from under-represented backgrounds who otherwise are unable to afford the ever-increasing price of HE. As part of the present fees regime, universities charging more than the basic full-time tuition fee of $£ 6,165$ are legally obliged to submit Access Agreements (until September 2019, when they become Access and Participation Plans) to the OfS demonstrating how they intend to spend $30 \%$ of additional fee income on WP activities, which concern not just access, but retention during study and progression to employment. In response to criticism of overspend on fee waivers as means of increasing recruitment and underspend on retention and progression, spending on financial support for retention and progression has increased from 26\% in 2012 to $51 \%$ in 2017 of overall OFFA Access 
Agreement funding (Bolton, 2018: 12). Government spending on access in 2017/18 was estimated at $£ 412$ million and the requirement that Universities charging over the $£ 6,000$ threshold spend a portion of variable fee income on OFFA/OfS approved access agreements raised University spending on access to $£ 725$ million in $2014 / 15$ and a projected $£ 780$ million in 2017/18 (Bolton, 2018: 11).

This response to the increase in fees perpetuates belief that HE is an indispensable pathway to enhanced earnings through graduate employment. Indeed, the notion that participation must be widened in order to reflect a societal commitment to meritocracy, has led to an outreach focus on recruitment, circuitously, as both a means and end for WP activity (see Johnson, 2016; Harrison \& Waller, 2017). Like many fetishistic approaches to issues (see Johnson and Mabon, 2018), this fosters additional deficits in WP without addressing the basic problem of inequality in society as a whole. This is apparent in the finding of the Social Mobility Commission that there is a fundamental inequality of outcome that still separates working class from middle class graduates who achieve the same grades and degrees (Friedman, et al., 2017). In terms of progression to Britain's 'traditional professions', medicine, law and academia, Friedman, et al. (2017: i) claim that ' $73 \%$ of doctors are from professional and managerial backgrounds and less than $6 \%$ are from working-class backgrounds'. In terms of pay, there is a clear gap between graduates from working-class backgrounds and those from professional and/or managerial backgrounds, with the former earning up to $17 \%$, a full $£ 6,800$ a year, less than the latter (Friedman, et al., 2017: 17). Even accounting for other factors identified as having a tangible effect on income equality, such as intergenerational stability, educational attainment, gender and ethnicity, the Social Mobility Commission state that there is still a 7\% pay gap, of $£ 2,242$ a year, attributable to class background (Friedman, et al., 2017: 19). In part, this gap stems from differences in institutionalisation.

\section{Institutions, institutionalisation and social capital}

As graduates from disadvantaged backgrounds receive fewer rewards for achieving the same undergraduate outcome, it follows that there must be a range of non-academic factors that benefit disproportionately graduates from professional backgrounds and/or that qualifications have only have a limited effect on determining perception of the value of individuals in the labour market. One institutional factor that exacerbates this gap is the trend of lower ranked universities' recruiting disproportionately high numbers of students from disadvantaged backgrounds (Burnett, 2016) and higher ranked universities recruiting disproportionately high numbers of students from privileged backgrounds and with higher A Level grades (Siddiqi, 2017).

Privileged students are heavily institutionalised - that is to say, embedded and acculturated into institutions - at an early age in ways that confer key advantages in accessing higher ranked HE institutions that then, because of their extra-curricular capacities and links with employers, institutionalise them in ways that facilitate access to higher paid, higher status jobs (see Marjoribanks, 2002: 12). At the same time, because employers discriminate against graduates of lower ranked universities, those graduates may face hurdles irrespective of the excellence of their work during undergraduate study. At each stage of an individual's academic career and transition into work, the extent to which they are institutionalised into elite institutions has a clear effect on outcomes, often for very straightforward reasons: they are party to social networks that open up opportunities unavailable to outsiders (see discussion in Reay, David and Ball, 2018). By way of illustration, not everyone has Toby Young's Professorial father to persuade an admission officer to allow their son entry to Oxbridge (Jones, 2018).

In effect, individuals face inequalities of social capital (see Hart, 2018; Ciabattari, 2012), which Bourdieu (1986: 249) describes as 'The sum of the resources, actual or virtual, 
that accrue to an individual or a group by virtue of possessing a durable network of more or less institutionalised relationships of mutual acquaintance and recognition (Bourdieu, 1986: 249). Social capital is fostered socially by being institutionalised in ways that explain and make apparent particular interests and present means by which those interests can be pursued in concert with others (see Jæger and Karlson, 2018: 778). Exclusion from institutions perpetuates disadvantage and compounds and exaggerates inequality throughout an individual's life, insofar as, at each stage, that person misses opportunities to advance their interests, stifling potential and diminishing outcomes. Deficits in social capital reinforce and embed disadvantage culturally, fostering collective senses of alienation, diminishing aspiration and creating burdens of low expectations, undermining social mobility in the process (see Putnam, 2000). Drawing on Lin (2000), access to resource-rich networks is characterised by 'access to information from and influence in diverse socioeconomic strata and positions', while individuals embedded within resource-poor networks 'share a relatively restricted variety of information and influence' (Lin, 2000: 787). As such, it is vital that WP programmes ensure that WP students are not only exposed to, but actively supported in engaging with, the resourcerich networks available within HE institutions.

Given the complex findings on inequality in graduate earnings, there is good reason at first sight for efforts to deal with disadvantage to focus centrally on the institutional value of university (see Hart, 2018). Johnston (2004: 17) notes three clear foci: Active connections between people, participation in civic affairs, and positive reciprocity within communities. It is quite possible for an HE student to attain their degree without engaging with these factors. Students who live at home in an area of deprivation, who commute to campus and who have to work to fund their studies, are necessarily restricted in the networks to which they can glean access. They graduate with the same degree as their privileged peers, but with less social capital.

Indeed, even achieving parity in degree classification is an achievement, given the findings of the f such factors as the need to engage in employment (10+ hours per week) HEPI 2017 Student Academic Experience Survey. Living in the family home reduced perceived learning outcomes by $9 \%$, while working $10+$ hours per week by $8 \%$. With disadvantage necessarily undermining individuals' ability to engage in extra-curricular activities, it is little surprise that they feel that they receive a lower return on their investment (Neves \& Hillman, 2017: 25).

Vitally, however, simply being aware that social capital is a factor in determining outcomes is often a result of having social capital in the first place. As Paul Clarke (2017: 22) notes, we

need to see developing young people's social capital as a long-term investment and one which can transform higher education from an engine of social reproduction to the engine of social mobility it is at its best.

This ought to inform each stage of WP, from access, through retention to progression.

This is especially true in lower ranked, younger universities that lack the more robust and institutionalizing culture of older universities. This is indicated both by the perception of the value of degrees by employers and by the value that students themselves feel that they receive from their respective institutions (Neves \& Hillman, 2017: 15). In responding to this challenge, while branding may alter perspectives of external actors, such as employers (see Boliver, 2015), it cannot advance robust institutions capable of endowing students with social capital (see discussion in Reay, David and Ball, 2018). Branding has to stem from those institutions - it cannot compensate fully for their deficits.

Indeed, because institutions shape and foster social capital and because social capital shapes and fosters labour value it is essential that Higher Education Institutions (HEIs) focus clearly on enhancing social capital at access, retention and progression. There is good reason 
to believe that outreach programmes aimed at widening access ought to focus on explaining the importance of institutions as means of fostering social capital. This is particularly true of lower ranked universities that recruit a disproportionate number of disadvantaged students and face compound discrimination from employers as a consequence. This requires pedagogical competence in delivering content grounded in sociological, economic and political concepts, in addition to whatever subject content is delivered as part of subject- or discipline-specific recruitment. All of that depends upon substantive academic involvement in outreach work. How, though, do WP access programmes work in practice?

\section{WP prestige and practice}

The range of WP programmes is illustrated by online outreach material at five different universities in April 2018: University of Cambridge, University of Leeds, University of Kent, Coventry University and Anglia Ruskin University. The examples illustrate different types of HEI and, although Vikki Boliver (2015) has argued convincingly of the deficits in differentiating between different universities on the basis of, say, their membership of the Russell Group, it is valuable to do so in this context insofar as perception of the status of universities may serve to foster discrimination by employers.

By virtue of employer discrimination, the University of Cambridge has the least instrumental need to promote its institutional value in terms of social capital. However, it is, clearly, an institution fully aware of its institutional importance and its forms of outreach emphasise the value of life at Cambridge in terms of institutional benefits and social capital (University of Cambridge, 2018a). Cambridge WP programmes target high-attaining students from disadvantaged backgrounds by providing realistic experience to school pupils of Cambridge teaching in their preferred subject and realistic experience of university life through facilitating access to Colleges and the city. As we might expect, given its elite status, rhetorically, the programmes emphasise attainment (in terms of grades) and understanding (in terms of what the HE experience represents), transparently seeking to engage only the most able students (see HE+ University of Cambridge, 2018b). There is no mention of labour market value or career progression for prospective students because a Cambridge degree is recognised, implicitly and explicitly, as a means of advancing labour value. In effect, Oxbridge in general has simply to perpetuate itself, in part through exclusion on the basis of A Level attainment, in order to sustain the social capital it confers on students and graduates.

The University of Leeds benefits from its status as a Red Brick, Russell Group institution (see University of Leeds, 2018a), but does not have the same elite status as Oxbridge (see Boliver, 2015). It also does not have the same conscious sense of its own implicit provision of social capital to advance the interests of those who need that social capital most. It makes clear that it needs to take additional steps to achieve the same outcomes as Oxbridge. This is apparent in the institution's commitment to fostering a range of transferable skills as part of degree schemes, which contributed to its 2017 TEF Gold Rating, and in the LeedsforLife programme's commitment to encouraging students to 'recognise the value of everything [they] have done' (University of Leeds, 2018b). In this context, Leeds' outreach programme, 'Access to Leeds', has clearly been effective: Leeds is the fifth largest University in the UK by student population (HESA, 2018) and 26\% of Leeds' undergraduate students come from disadvantaged backgrounds (University of Leeds, 2018c). However, the online materials do not recognise the difference in social capital between middle-class and working-class students and focuses centrally on advancing subject and study skills, rather than fostering the rounder set of understandings regarding networks that enable individuals to close gaps in outcomes.

As a Plate Glass, non-Russell Group institution, University of Kent clearly has a significant academic history, albeit without the perception among employers and the general public of quality and elite status associated with Russell Group institutions. Kent places 
particular focus on debunking the idea of the 'typical University student' in its outreach narrative. This is clearly well-meaning, but seems to ignore the fact that there clearly is such a thing as a 'typical University student' and that that 'typical' individual will have certain advantages in terms of accessing the institutional benefits of HE. That said, Kent is one of the few institutions that actively seeks to engage younger school students in understanding the value of HE participation delivering programmes consistently from Year 7 to Years 12-13 - an engagement much more likely to close gaps than forms pitched exclusively at older students (see Fellows, 2017). By targeting students at over 45 non-selective partner schools, the University aims 'to support learners throughout their secondary school careers so that they are able to make informed choices about post 16 education and university study' (University of Kent, 2018). However, while there is a focus on attainment, there is a clear deficit in terms of examining, discussing and illustrating the particular challenges that those from excluded backgrounds face in converting their attainment into labour market value. As such, the programmes suffer from dearth of concern for social capital apparent in the Oxbridge and Russell Group examples precisely because the university needs to enhance its social capital in order to deal with discrimination among employers and because prospective students need that focus in order to understand disadvantage.

Coventry University highlights the challenge for WP even in more successful post-1992 institutions (see Coventry University, 2017a; 2018a). There is little explicit concern for the reasons for students to engage in outreach nor for the means by which those students might access the institutional benefits of HE. While the 'Phoenix Partner' programme claims to deliver tailored talks to support schools in 'raising [their] students' aspirations and preparing them for University' (Coventry University, 2017b), the resources make clear that grades and attainment are the primary, almost sole, focus of outreach. Student ambassadors do deliver a session entitled 'Student Life', in which they 'give students a real insight into what lies ahead at university' (Coventry University, 2017b), but the engagement focuses on applications, finances and employment rather than on examining the institutional benefits of HE in general and Coventry in particular. University appears as a non-subject-specific end in and of itself, rather than as a mechanism through which to acquire social capital (Coventry University, 2018b).

Similarly, Anglia Ruskin University (ARU) advances the idea that attending HE is an intrinsic solution to individual disadvantage. Online ARU outreach material appears less well resourced than the institutions above, and rather than setting its own targets, ARU states that it 'aims to support the Government's goals' (Anglia Ruskin University, 2018a; see also, 2018b), which is rare given general HE rhetoric of ownership over targets and programmes. ARU's outreach events revolve around study support, personal statement production and UCAS application processes. There is little focus on subject-specific courses or events, with subject taster sessions run by individual departments. Moreover, while there is concern for diversity of identity, there is not explicit concern for class, which is a significant hurdle to graduation's conferring the same labour value on all (see Anglia Ruskin University, 2018c)

While Coventry's and, especially, ARU's approaches may stem from a comparatively embryonic institutional university culture (however rich their polytechnic history may be), nonacademic, non-subject-specific outreach programmes fail to explain the institutional sources of disadvantage and focus on labour market value. This is problematic both for students and institutions, since the former may raise claims of mis-selling if degrees fail to enhance graduate outcomes (see Neves and Hilman, 2017: 12-18).

Moreover, these post-1992 institutions present, unintentionally, an exclusionary narrative absent in the Oxbridge approach: students targeted by outreach are presented with a fundamentally different projection of university life than 'normal' or mainstream students, with concern for attendance and qualification, rather than acculturation. Accordingly, the 
universities that do the most to widen access may perpetuate disadvantage by combining relative dearth of subject-specific focus needed to acculturate students into particular courses of study with relative dearth of focus on engagement with the causes of and responses to disadvantage other than the implication that university attendance is a means and end in and of itself. This serves simply to present the university as a vassal through which to attain grades, rather than an institution capable of fostering social capital and advancing interests holistically. Unfortunately, post-1992 universities need this sort of work in order to enhance their intrinsic value and challenge discrimination against graduates by employers. How might they overcome this challenge?

\section{Rethinking Disadvantage}

'Rethinking Disadvantage' (Johnson, 2018b) was developed as part of a Politics and International Relations WP programme at Lancaster University aimed predominantly at disadvantaged Key Stage 4 and 5 students. In keeping with guidance produced by the Association for Academic Outreach (Johnson, et al., 2018: 14), the programme was grounded specifically in explaining disadvantage, in subject-specific terms, and presenting $\mathrm{HE}$ institutions as means of advancing interests through social capital. 'The programme was shaped by the findings and material of a participatory project, entitled 'A Cross-Cultural Working Group on "Good Culture" and Precariousness' (see Johnson, 2017), which sought to explain and present policy responses to disadvantage. Interviews, presentations and discussions were recorded on film during the production of two documentaries, which were uploaded to a designated project website (Johnson, 2017) and YouTube archive (Johnson, 2018a). Among other findings, the project argued that the dissolution of institutions and disruption of social networks through successive neoliberal reforms had served seriously to strip people of social capital and to diminish the capacity of members of excluded groups to advance their interests individually and collectively.

'Rethinking disadvantage' used the audio-visual materials and findings from the project to shape institutional, social capital-based content capable of explaining sources of disadvantage to those who need understanding most and to create pathways to HE (see discussion in Jackson and Price, 2017). While the programme sits firmly within Politics as a subject area, it draws upon ideas and concepts from Sociology, History and Economics in order to explain phenomena in detail. In this respect, the content is clearly academic and subjectspecific, but made accessible through engagement with participating students' own familial and community experiences and histories.

This raises a number of ethical concerns regarding students' examination of their circumstances, since the outcome of that examination may be to highlight the ways in which they are disadvantaged. However, the programme is designed transformatively to destigmatise disadvantage and to highlight the ways in which it is inflicted arbitrarily on individuals through political processes that are anything but natural and inevitable. The intention has been to ensure that students who do face obstacles understand that these obstacles are not their fault, need to be understood in order to be overcome and that simply attending university may not be sufficient to ensure the sort of outcomes they desire.

The module is designed to be delivered either by teachers in schools teaching in Politics, Sociology, Human Geography, History, Citizenship Studies and Media Studies or by academics from Lancaster as part our Politics WP programme. It is fully resourced, online and open access, with instructions for teachers, PowerPoint decks with lecture notes for each of the sessions, a YouTube archive of audio-visual materials and links to basic readings and sources.

There are five two-hour sessions (one per week), each advancing a narrative explanation for disadvantage and an examination of means of responding individually and politically to the structures that inflict that disadvantage: 
- Session 1: What is disadvantage?: This session introduces the problem of disadvantage and tries to highlight the ways in which public perceptions of disadvantage differ from reality.

- Session 2: Why are people disadvantaged?: This session tries to explain disadvantage by drawing on several different examples in which people are disadvantaged by virtue of their racial, ethnic, cultural or class identity.

- Session 3: How can we challenge disadvantage economically?: This session analyses the economic basis of disadvantage and explores a range of economic means of challenging inequalities.

- Session 4: How can we challenge disadvantage politically?: This contrasts approaches to institutions over the past several decades through reference to students' family histories and introduces contemporary policy responses.

- Session 5: How can education challenge disadvantage?: This session explores means of individuals challenging disadvantage highlighting the ways in which social capital, rather than grades alone, contribute to people's outcomes.

Throughout, students are asked to engage with oldest relatives or other older people from their communities, including teachers at their schools, with whom they have safe contact. The intention is to enable students to map changing attitudes to institutions, to identify shifts in social capital and to examine the political reasons for disadvantage. How though might such an approach affect students?

\section{Method}

This study combined a practical action method deployed to solve the 'practical problem' of ineffective WP outreach programmes and to 'produce guidelines for best practice' for the sector on those programmes (Denscombe, 2010: 6). The research is intended to serve the needs of those attempting to advance WP through considered illustration and reflection on a particular experience. Such an approach, which combines practical action research and case study in fostering critical action research, has natural synergies with participatory methods insofar as the latter involves collaborative transformation of people's lives (see McAllister and Vernooy, 1999: 48-59; Freire, 1973). In this respect, it is important to note that 'best practice' will differ from institution to institution, since the content of the institutional justification for HE differs from university to university and subject area to subject area. The research was conducted during the development and implementation of the programme by us, as academic practitioners on our own practice as we were engaged in it (Edwards and Talbot, 1994: 52). We did not seek to examine its applicability in all disciplines and institutions, but to establish those elements that can be applied generally across the sector.

Because of the cost of Lancaster scholars running each of the five sessions in schools, we ran 12 one-off workshops that combine and condense key elements of each of the sessions either to support delivery of other elements of the module or to encourage schools to examine the issues at play with or without further reference to the module. It is these sessions that form the basis for our discussion here.

The schools approached either featured in Lancaster University's Access Agreement 'target list' or had a significant number of disadvantaged students whose teachers wished to introduce to the topic, generally with access to HE in mind. Whereas engagement with Access Agreement 'target list' schools was deemed to meet WP requirements by Lancaster, engagement with students from schools outside the list was determined by the standard OfS (2018) criteria. We engaged with 10 schools from the OFFA list and 2 from outside the list but 
with a significant body students from WP backgrounds. All of the schools were from the North of England.

Students were asked to prepare for the session by speaking with older relatives about institutions in general and education in particular in order to be able to examine the following questions:

- What are the differences between the organisations and institutions that played a role in your grandparents' lives and those in your lives?

- What are the differences between the way that your grandparents viewed the NHS when they were young the way that you view it today?

- Are there any differences between your views and the views of your grandparents with regard to the notion of nationalised organisations, industries or companies?

- Do you agree with your grandparents' assessment of whether society is more equal today or during their youth?

- Why might you have different views to your grandparents?

- What similarities and differences are there between the school experiences of your parents or grandparents/great grandparents and your own?

- How has education contributed to social mobility in your family history?

- What relationships and basic skills do you need to secure employment?

- How might university support those relationships and basic skills?

The sessions were delivered during 2017/2018 to Key Stage 5 students taking a range of A Levels and NVQs in schools by one of two academics with the support of teachers at the host schools.

We deployed a questionnaire at the end of the sessions to assess the impact of the teaching on five learning outcomes: i) increased understanding of the reasons for disadvantage; ii) increased interest in and knowledge of family/community history with regard to disadvantage and social mobility; iii) increased knowledge of institutions and their role in advancing interests; iv) increased understanding of political responses to disadvantage; v) increased interest in continuing to HE. Participants were presented both with a table quantifying impact with regard to each of those outcomes and a series of open-ended questions soliciting qualitative responses with regard to each outcome and a final 'any other comments' option: i) Did you find anything surprising about the reasons for disadvantage?; ii) What did you learn about your family's or community's history and how it has influenced your opportunities?; iii) What did you learn about the importance of institutions, such as the state and the education system?; iv) What did you learn about political responses to disadvantage?; v) In what ways have you learned more about the role Higher Education can play in challenging disadvantage?; vi) If you have any other comments about or suggestions for other activities/sessions please add them below.

During the ethics approval process, it was agreed that we would assure participants of anonymity by asking only for school name and no other identifying information, such as home postcode or subjects studied. A lengthy participant information sheet emphasised that participation was voluntary and anonymous. Participating students were given at least ten minutes in which to complete the forms. The completed hard copy forms were entered into and analysed by Qualtrics.

\section{Results}

179 students from the 12 schools completed the questionnaire. The number of students completing the questionnaire at each school ranged from 7 to 32. As Table 1 illustrates, the data indicates that the intervention was effective in achieving five learning outcomes: i) $76.3 \%$ 
of participants agreed that workshop increased understanding of the reasons for disadvantage, with $9.25 \%$ disagreeing; ii) $65.5 \%$ agreed that the workshop increased understanding of family and/or community histories, with $9.94 \%$ disagreeing; iii) $69.71 \%$ agreed that the workshop increased understanding of the importance of institutions, with $8 \%$ disagreeing; iv) $63.43 \%$ agreed that the workshop increased understanding of political responses to disadvantage, with 9.14\% disagreeing, and v) $56.64 \%$ agreed that the workshop encouraged continuation to HE, with $8.09 \%$ disagreeing.

Table 1. Breakdown of ordinal data by learning outcomes Q1 - To what extend do you you agree or disagree with the following statements?...

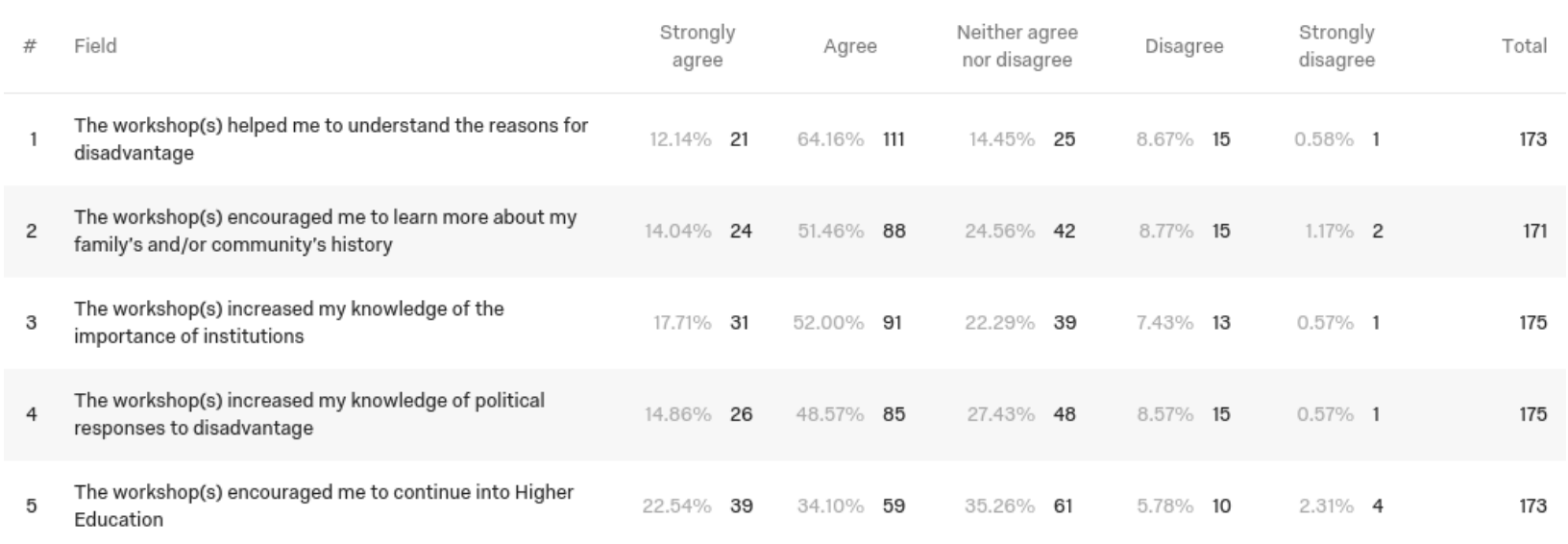

Showing Rows: 1 - 5 Of 5

Interestingly, the percentage of participants unaffected (neither agree nor disagree) by the sessions ranges from $14.45 \%$ in terms of the reasons for disadvantage up to $35.26 \%$ in terms of continuation to $\mathrm{HE}$.

The qualitative data helps to explain some of this trend. Participant 87 noted that the reasons for disadvantage were often complex, pointing out that they were surprised at 'the amount of factors which could lead to inequalities/disadvantages', while Participant 116 added that 'small changes can have a large effect on a local community'. This speaks to the way in which the sources of disadvantage are inadequately explained to those who are disadvantaged. Indeed, Participant 99 argued that, until the session, the reasons for disadvantage were opaque and had not previously been examined within the school system, before highlighting the ways in which 'policies over the last 40 years have affected disadvantage'. Participant 89 stated that 'things have changed from generation to generation', while Participant 4 claimed that the workshops were facilitating 'learning about what are the real disadvantages in the world', indicating transformative impact on thinking beyond the non-institutional foci of existing programmes.

Participants talked of the importance of engaging with family members in order to understand the reasons for their position in society. Going beyond explanations grounded in 'attainment', Participant 12 cited 'family standard of education and employment', Participant 40 the dissolution of community cohesion and Participant 131 the absence of a 'stable income' as reasons for trans-generational disadvantage. There was discussion of the ways in which social processes affected participants' places in society. In this regard, Participant 14 stated that they learned that 'whether my mum or dad went to uni influenced my choices', while Participant 66 noted that 'society adds pressure for advantages \& disadvantages in life'. Vitally, having not previously engaged with their local history, Participants 47, 56, 121, 151 and 13 cited the decline of traditional industries as having affected their generation's status, with mining and work both cited as examples of once important activities that had been lost to those 
in the present. This indicates impact on students' ability to apply analysis of large institutional processes to their own circumstances.

Vitally, participants also noted the transformative importance of institutions. Participant 56 stated that 'being tied to a certain institution may decrease your chances of being at a disadvantage more than I thought', while Participant 122 noted that institutions 'benefit different people in different ways'. Participants also highlighted pathways to social mobility through institutions. Participant 155 claimed that 'society is built around them [institutions]', while Participant 164 asserted that institutions can 'help people from poor backgrounds to earn money and move into a new class'. Participants 17, 18, 68, 118, 132, 133, 134 and 150 also highlighted awareness of new political approaches to disadvantage, such as Universal Basic Income. This ties together comprehension of the value of institutions in fostering social capital with practical means of pursuing interests.

Finally, there was a clear contrast in responses to the effect of the sessions on interest in applying to HE. Participant 128 claimed that 'universities can help to increase the amount of people and businesses a person knows', while Participant 131 asserted that 'I have learned that education will allow better life opportunities'. More controversially, Participant 155 stated 'that disadvantage is based on ignorance'. However, other participants suggested that they were unaffected and already intended to apply to HE. Participant 173 , for example, claimed that they 'knew the offer is there for people from my backgrounds which not have had this opportunity', while Participant 64 stated that 'Education is not just a way to get a job'. This reflects both the ways in which life paths are set by KS5 and impact on students' thinking about the institutional value of their next steps in terms of social capital.

Discussions with teachers suggested that other participants had different options, such as apprenticeships or, in reflecting on the teaching, decided to pursue alternatives. The fact that any increase in interest in applying to HE among seriously alienated and excluded students was felt suggests genuine impact in the sessions. The impact on actual applications will not be known until 2019/2020 when access can be established through engagement with the schools and the Higher Education and Access Tracker: HEAT, which is beyond the scope of this article.

\section{Discussion: the challenges of institutional approaches to WP}

The results indicate that the programme was relatively successful in each of the learning outcomes. The impact must be understood in the context of participating students being from groups that are among the least likely of all KS5 students to access HE precisely because they are alienated and excluded. While that would seem to be a precondition of WP programmes, there are ways in which some WP groups may be easily accessible targets for recruitmentbased activities, including engagement with Independent or higher performing schools, including grammars, which have students who qualify for WP programmes but otherwise benefit from above average levels of academic support (see example in Pells, 2017).

The students with whom this programme engaged were not easily accessible targets: they often were not taking core A Level subjects, were sometimes taking NVQs, and often did not consider continuing into $\mathrm{HE}$ as a viable choice before taking the sessions. Moreover, their schools faced a range of pressures in terms of resources and communication between members of staff that undermined smooth delivery of the outreach sessions. In 5 out of 12 cases, the teacher responsible for the group did not ask the students to complete the homework, mostly because they had not been informed by the HE co-ordinator, Head of Sixth Form or other member of staff who liaised with us that the homework was a precondition of participation. In other instances, even when students had been prepared, access to the YouTube videos had not been permitted on school servers, meaning that, in two instances, the sessions were interrupted by IT technicians providing access and, in another instance, the session proceeding without the videos at all. This is all an inevitable consequence of under-resourced, over-burdened teachers 
and support staff being asked to engage in work that is of potential medium- to long-term importance to students, but not of immediate or significant benefit to individual subject area teachers.

It is for this reason that WP is a responsibility for HEIs. It is only HEIs that can reach students in most need of guidance about the sources of disadvantage and means of achieving mobility. As such, the programme illustrates the kind of work needed to make an impact, albeit with the proviso that more investment of time and resources is needed than was apparent over the course of the study in 2017-2018. It is vital for HEIs are both aware of the importance of their role in fostering social capital and allocate resources to making this clear to WP students. It is particularly important for those HEIs that are less prestigious to adopt this position consciously. An approach such as Rethinking Disadvantage necessarily ensures introspection about a university's place in the world. It calls for universities, such as the post-1992 cohort, to cultivate and emphasise their institutional heritage as transformative, welcoming bodies of mass education and deliverers of outstanding teaching, particularly in vocational subjects, since this has done so much to contribute to contemporary Britain (see Scott, 2012).

Our teaching benefited from our orientation in Politics and our ability to deliver content grounded in social scientific disciplines, but other disciplines can combine basic explanation of the importance of institutions with subject-specific engagement on a range of topics. Explaining why social capital is important is just as important for prospective engineers as it is politicians. This is particularly important in the context of potentially misleading outreach grounded in labour market value. In order for students to benefit institutionally from HE, they have to be enthused about a very specific set of ideas and practices. This cannot be achieved independently of academic engagement and cannot be subject-neutral (see Association for Academic Outreach 2018). This is one reason for academics being encouraged to view outreach as integral to their work. Rethinking Disadvantage illustrates both the ways in which impactful outreach depends on academic input and, if taken seriously, ought to be considered core academic business.

\section{Conclusion}

The universities that are seen as being elite benefit precisely because of that perception, whether or not, as Boliver $(2013 ; 2015)$ suggests, that perception is grounded in reality. These universities are aware of their institutional value, invest in their institutions and use those institutions as the basis for their recruitment, disproportionately recruiting higher achieving, less disadvantaged students in the process. Their WP activities often combine social capitalgrounded arguments with genuine academic content, attracting students to their institutions and specific subject areas, meaning that subsequent issues of retention and progression are mitigated at the outset. The research presented here has clearest implications for those institutions that do the most to provide access for students from disadvantaged backgrounds. Rather than presenting subject-neutral, labour market value arguments, it is imperative that Post-1992 institutions, in particular, highlight and embolden the pathways that they are already creating to graduation, employment and adulthood and combine rich, institutional justifications for HE with subject-based, academic outreach that provides a particular, rather than general, source of enthusiasm for study.

'Rethinking Disadvantage' highlights the challenges of advancing such an approach, but also presents an evidential basis in support of such efforts. Quite aside from instrumental, recruitment-based concerns for the health of departments, we have a civic duty to support the society that has shaped us through its institutions by creating and highlighting institutional pathways for those alienated and excluded by myriad inequitable policies and phenomena.

\section{References}


Anglia Ruskin University (2018a) 'Collaborative Outreach Projects', Anglia Ruskin University, at https://www.anglia.ac.uk/schools-and-colleges/collaborative-outreachprojects (accessed: 06 August 2018).

Anglia Ruskin University (2018b) 'Working With You', Anglia Ruskin University, at https://www.anglia.ac.uk/schools-and-colleges/working-with-you (accessed: 15 August 2018)

Anglia Ruskin University (2018c) 'Equality and Diversity', Anglia Ruskin University, at https://www.anglia.ac.uk/student-life/equality-and-diversity (accessed: 06 August 2018).

Association for Academic Outreach (2018) Evidence Submission to the UPP Civic University Commission, Lancaster: Association for Academic Outreach, http://wp.lancs.ac.uk/afao/research/evidence-submission-to-the-civic-universitycommission-2018/ (accessed: 06 August 2018).

Boliver, V. (2015) 'Are there distinctive clusters of higher and lower status universities in the UK?', Oxford Review of Education, 41, 5: 608-627.

Boliver, V. (2013) 'How fair is access to more prestigious UK Universities?', British Journal of Sociology, 64, 2: 344-364.

Boliver, V. (2010)' Expansion, differentiation, and the persistence of social class inequalities in British higher education', Higher Education, 61, 3: 229-242.

Bolton, P. (2018) 'Tuition Fee Statistics', House of Commons Working Paper Number 917, London: HMSO.

Bourdieu, P. (1986) 'The Forms of Capital' in J. Richardson (ed) Handbook of Theory and Research for the Sociology of Education, Westport, CT: Greenwood, pp. 241-258.

Burnett, K. (2016) 'Are low-ranking universities bad for our children?', The Telegraph, 22 April, at https://www.telegraph.co.uk/education/2016/04/22/are-low-rankinguniversities-bad-for-our-children/ (accessed: 06 August 2018).

Chan, T. W. and Boliver, V. (2013) 'The grandparents effect in social mobility: evidence from British birth cohort studies', American Sociological Review, 78, 4: 662-678.

Ciabattari, T. (2010) 'Issue in Education: Cultural Capital, Social Capital, and Educational Inequality', Childhood Education, 87, 2: 119-121.

Clarke, P. (2017) 'Who you know: The importance of social capital in widening participation' in HEPI (eds.) Where next for widening participation and fair access? New insights from leading thinkers: HEPI Report 98, Oxford: HEPI, pp. 17-22.

Coventry University (2017a) 'Six Reasons to Choose Coventry University', Coventry University, at https://www.coventry.ac.uk/study-at-coventry/6-reasons-to-choosecoventry-university/ (accessed: 06 August 2018).

Coventry University (2017b) 'Teachers and Partners: How we can help', Coventry University, at https://www.coventry.ac.uk/study-at-coventry/parents-and-teachers/teacherspartners/ (accessed: 06 August 2018).

Coventry University (2018a) Coventry University Homepage (online) at https://www.coventry.ac.uk/ (accessed: 28 July 2018)

Coventry University (2018b) 'Pre-16 Outreach Activities and Events', Coventry University, at https://www.coventry.ac.uk/cuc/study/outreach/outreach-activities/ (accessed: 06 August 2018).

Cambridge University (2018c) 'Why Higher Education?', Coventry University, at https://www.unitasterdays.com/EventDetails.aspx?ID=23824 (accessed: 06 August 2018).

Denscombe, M. (2010) The Good Research Guide, Maidenhead: Open University Press. 
Department for Education (2017), Widening Participation in Higher Education: 2017, at https://www.gov.uk/government/statistics/widening-participation-in-highereducation- 2017 (accessed: 15 August 2018)

Department for Education and Employment (1998) Higher Education for the 21st Century: response to the Dearing Report, London: HMSO.

Edwards, A. and Talbot, R. (1994). The Hard-pressed Researcher. London: Longman.

Fellows, T. (2017) 'A reply to O’Sullivan, O’Tuama and Kenny', Global Discourse, 7, 4: 543547.

Freire, P. (1973) Education for Critical Consciousness, New York: Continuum.

Friedman, S. Laurison, L. Macmillan, L. (2017) Social Mobility, the Class Pay Gap and Intergenerational Worklessness: New Insights from The Labour Force Survey, London: Social Mobility Commission.

Harrison, N. and Waller, R. (2017) 'Evaluating outreach activities', Perspectives: Policy and Practice in Higher Education, 21: 81-87.

HESA (2018) 'HE Student Enrolments by HE provider 2016/17', HESA, at https://www.hesa.ac.uk/data-and-analysis/students/table-1 (accessed: 06 August 2018).

Jackson, L. H. \& Price, C. (2017) 'Illuminating constellations of peer mentoring', Innovations in Education and Teaching International, at doi:10.1080/14703297.2017.1417887 (accessed: 06 November 2019).

Jæger, M. M. \& Karlson, K. (2018) 'Cultural Capital and Educational Inequality: A Counterfactual Analysis', Sociological Science, 5: 775- 795.

Johnson, M. T. (2013) Evaluating Culture, London: Palgrave.

Johnson, M. T. (2016) 'Communicating politics: active learning and integrating entry, teaching and exit strategies', British Journal of Educational Studies, 64:3, 315-335.

Johnson, M. T. (2017) 'Home', A Cross-Cultural Working Group on "Good Culture" and Precariousness, at http://wp.lancs.ac.uk/good-culture/ (accessed: 30 July 2017).

Johnson, M. T. (2018a) "A Cross-Cultural Working Group on "Good Culture" and Precariousness', YouTube,

at https://www.youtube.com/channel/UCFYnoCKbEDJAliUeJgBhQ1g/videos (accessed: 30 July 2017).

Johnson, M. T. (2018b) 'Rethinking Disadvantage', Lancaster University Open Learning, at https://openlearning.lancs.ac.uk/course/view.php?id=166 (accessed: 30 July 2017).

Johnson, M. T., Danvers, E., Hinton-Smith, T., et al. (2019) 'Higher Education Outreach: Examining Key Challenges for Academics', British Journal of Educational Studies (online first), at https://doi.org/10.1080/00071005.2019.1572101.

Johnson, M. T. and Mabon, S. (2018) 'Fundamentalism: examining the role of public reason in "non-liberal" approaches to "unreasonable" doctrines', Australian Journal of Political Science, 53, 2: 195-210.

Johnson, M. T. and Mutton, R. (2018) 'Widening Participation: Developing 'Academic' Programmes in Light of Recruitment Pressure', Journal of Widening Participation and Lifelong Learning, 20, 1: 123-145.

Johnston, G. (2004) 'Healthy, wealthy and wise? A review of the wider benefits of education', Treasury working paper 04/04, Wellington: New Zealand Treasury.

Jones, E. E. (2018) 'A well-connected, ambitious blowhard: Toby Young is just what education doesn't need', Evening Standard, 4 January, at https://www.standard.co.uk/comment/comment/a-wellconnected-ambitious-blowhardtoby-young-is-just-what-education-doesn-t-need-a3731921.html (accessed: 06 August 2018).

Hart, C. S. (2019) 'Education, inequality and social justice: A critical analysis applying the Sen-Bourdieu Analytical Framework', Policy Futures in Education, 17, 5: 582-598. 
Lancaster University (2018) 'Our Reputation', Lancaster University, http://lancaster.ac.uk/about-us/rankings-and-reputation/ (accessed: 06 August 2018).

Lin, N. (2000) 'Inequality in Social Capital', Contemporary Sociology, 29, 6. 785-795.

Marjoribanks, K. (2002) Family and School Capital: Towards a Context Theory of Students' School Outcomes, Dordrecht, Netherlands: Kluwer.

McAllister, K. and Vernooy, R. (1999) A guide for monitoring and evaluating participatory research, Ottawa: CBNRM.

Neves, J. and Hillman, N. (2017) Student Academic Experience Survey, Heslington: HEA.

OFFA (2018) 'Final AA-Lancaster University', National Archives, at http://webarchive.nationalarchives.gov.uk/20180511111930/https://www.offa.org.uk/ access-agreements/searchresult/?prn=10007768 (accessed: 06 August 2018).

Pells, R. (2017) 'Bristol University offers third of places on disadvantaged pupils scheme to private school students', The Independent, 2 March, at https://www.independent.co.uk/student/news/bristol-university-criticised-third-ofplaces-disadvantaged-pupils-scholars-scheme-private-school-a 7607546.html (accessed: 06 August 2018).

Putnam, R. D. (2000) Bowling alone: The collapse and revival of American community, New York: Simon \& Schuster.

Reay, D., David, M. and Ball, S. (2001) 'Making a difference? Institutional habituses and higher education choice', Sociological Research Online, 5, 4, at http://www.socresonline.org.uk/5/4/reay.html (accessed: 06 November 2019).

Scott, P. (2012) 'It's 20 years since polytechnics became universities - and there's no going back', The Guardian, 3 September, at https://www.theguardian.com/education/2012/sep/03/polytechnics-becameuniversities-1992-differentiation (accessed: 06 August 2018).

Siddiqi, H. (2017) 'Who's Who study sheds new light on power of old boy network', The Guardian, 30 October, at https://www.theguardian.com/inequality/2017/oct/30/whoswho-study-sheds-new-light-on-power-of-old-boy-network (accessed: 06 August 2018).

Social Mobility Commission (2017) The class pay gap within Britain's professions at https://www.gov.uk/government/publications/the-class-pay-gap-within-britainsprofessions (accessed: 15 August 2018)

Sullivan, A., Parsons, S., Green, F. and Wiggins, R. (2016) 'Social origins, elite education and elite destinations', Centre for Longitudinal Studies Working Paper 2016/5, London: Centre for Longitudinal Studies.

University of Cambridge (2018a) 'Access and Participation Plans', University of Cambridge, at https://www.undergraduate.study.cam.ac.uk/find-out-more/wideningparticipation/access-and-participation-plans (accessed: 06 August 2018).

University of Cambridge (2018b) 'HE+', University of Cambridge, at https://www.undergraduate.study.cam.ac.uk/find-out-more/widening-participation/heplus (accessed: 06 August 2018).

University of Cambridge (2018c) 'Sutton Trust Summer Schools', University of Cambridge, at https://www.undergraduate.study.cam.ac.uk/events/summer-schools (accessed: 06 August 2018).

University of Kent (2018) 'Outreach in Schools', University of Kent, at https://www.kent.ac.uk/outreach/partner-kmpf/index.html (accessed: 06 August 2018).

University of Leeds (2018a) 'An Outstanding Education', University of Leeds, at http://www.leeds.ac.uk/info/130547/student_education/366/an_outstanding_education (accessed: 06 August 2018). 
University of Leeds (2018b) 'LeedsforLife', University of Leeds, at http://leedsforlife.leeds.ac.uk/ (accessed: 06 August 2018).

University of Leeds (2018c) 'Widening Participation', University of Leeds, at http://www.leeds.ac.uk/info/130547/student_education/367/widening_participation (accessed: 06 August 2018). 